\section{GP treatment of drug and alcohol problems}

Sir: To improve the quality and effectiveness of our services, we carried out a survey of local general practitioners asking about treatment of drug and alcohol problems. Questionnaires were sent to all 200 GPs practising in our catchment area which covers two inner London boroughs. They were asked to answer seven questions and supply additional comments both about their own practice and our service. We received 99 replies.

In response to "Do you offer your patients detoxification from alcohol?" $57 \%$ replied "Yes". Of those, over half used chlormethiazole which is recommended in the British National Formulary to be used only under in-patient supervision. The remainder used chlordiazepoxide or diazepam.

Although $84 \%$ of respondents routinely inquired about illicit drug use, $28 \%$ said that they did not work with patients who used illicit drugs. Just over half said they prescribed replacement drugs. The commonest drug offered for opiate addicts was methadone mixture, usually on a short reducing regime rather than maintenance or longer term reductions. Forty per cent did not feel they were receiving enough back up from our service. Respondents were asked to make suggestions as to how our service could be improved. The comments can be divided into four main areas.

(g) More communication.

(h) Earlier appointments. There seemed to be a discrepancy between waiting times as percetved by service providers and users. Our policy is to offer an appointment to all new referrals within 10 days of first contact. However, patients often told their GP they had to wait two to three weeks.

(i) More accessible service. This included access to telephone advice outside office hours and at weekends, and clinics located closer to the client's home or neighbourhood.

Not enough crisis intervention/ detoxification in-patient beds.

In carrying out this survey we have built a clearer picture of GPs' needs and hope that this will enable us to come closer in meeting those needs.
Another advantage is that it allows our service to inform the local purchasers of drug and alcohol services about what the GPs are offering and requesting, rather than be instructed by these agents of choice (the purchasers) about what they think the GPs and local community require.

Tim McGregor and Huw Thomas, Drug Users and Alcohol Liaison Team, 151 Blackfriars Rd. London SE1 8EL

\section{Suicides in prisons}

Sir: Concern has been expressed in the media and medical literature (Rowlands, 1995) regarding the disproportionate number of suicides in prisons. The suicide rate for young men aged 15 to 34 in prison is five to six times that of the general population (McClure, 1987).

In the Department of Health document The Prevention of Suicide Dr E. Dooley (1994) discusses Home Office guidelines (Circular Instructions 20/1989 and 52/1990) which outline preventive strategies to identify inmates at risk of suicide, reducing opportunities for selfinjury and ensuring education of staff. Dooley suggests difficulties with attempts to monitor risks, i.e. suicide risk is not constant in most cases; screening methods produce too many 'false positives' and cases who give little indication of intention may be missed.

While these points may have validity, studies in the United States suggest that a pro-active strategy, as well as a change in staff attitudes, may reduce prison suicides. An example is the Crisis Service Model (Hayes, 1994) implemented in New York State and involving 300 county jails with receptions exceeding 310,000 per year. There were four major components to their suicide prevention programme: establishing a prison policy with procedural guidelines; establishing suicide prevention intake screening guidelines; an eight-hour staff training programme; and training with a mental health practitioner manual. From 1985-1990, there was a reduction from 31 to 17 in recorded prison suicides (with three suicides occurring in 1993).

We would suggest that implementation and audit of similar models in the United Kingdom merit consideration.

DOOLEY, E. (1994) Prisons. In The Prevention of Suicide (eds. R. Jenkins et af pp. 104-108. London: HMSO. HAYES, L. M. (1994) Jail sulcide. Crisis, 2, 59-61. 
MCCLURE. G. M. G. (1987) Suicide in England and Wales, 1975-1984. British Joumal of Psychiatry. 160, 309-314. Rowlands, R. P. (1995) Deal with self harm in prisons (correspondence). British Medical Journal, 310, 127.

STEVEN F. REID and JOANNe TURNER, Sutton Hospital, Cotswold Road, Sutton SM2 5NF

\section{Working with young offenders: a contribution to forensic training in child psychiatry}

Sir: Specialist forensic training posts in child psychiatry are on the increase. However, in a survey of all child and adolescent psychiatry training schemes in the United Kingdom. Reder \& Lucey (1990) found that training with regard to young offenders was virtually absent. The rise in juvenile crime rates, together with a contraction in services equipped to deal with antisocial young people, have led to increasing concern about the health of young offenders, particularly regarding suicides among young offenders and about a core group of recidivist offenders.

There is therefore a need for specialist training placements which include involvement with young offenders. One such placement exists in North West Thames. The post is equally divided between a children and families department and the regional forensic out-patient department and includes an attachment to Feltham Young Offenders Institution (YOI).

The placement offers unique opportunities. The modes of presentation of disorders and the difficulties faced in treating them can be seen. An insight into the lives of young offenders is gained which provides a valuable understanding of the routes they have followed into crime. The trainee can begin to comprehend the influence of a prison environment on prisoners and on therapeutic relationships through experience of the establishment and knowledge of the Home Office.

With the increasing role of child and adolescent psychiatrists in the assessment and management of young offenders, this area of training can no longer be ignored. Such a placement is time efficient and provides unique training opportunities. It is strongly recommended to senior registrars interested in forensic adolescent psychiatry and would provide an important adjunct to any broadbased training scheme for senior registrars in child and adolescent psychiatry.
REDER, P. \& LUCEY, C. (1990) Child and adolescent psychlatry training schemes: recent developments. Psychiatric Bulletin. 14. 615-617.

A. J. HiLl-SMrTH, North West Thames Child Psychiatry Training Scheme, Adolescent Unit, Hill End Hospital, St Albans, Herts ALA ORB

\section{Severe hypertension associated with risperidone withdrawal}

Sir: We wish to report a case of severe hypertension associated with a rapid discontinuation of risperidone.

A 29-year-old man of mixed African and English origin with a nine year history of schizophrenia was admitted after he had been harassing residents at his hostel and expressing delusions. He had stopped his maintenance medication six months previously.

On arrival he was hostile and thought disordered. Blood pressure was 130/80. He was given oral chlorpromazine and a haloperidol decanoate depot of $200 \mathrm{mg} \mathrm{2-}$ weekly. Continuing disturbed behaviour led to first clonazepam (day 12, increasing gradually to $4.5 \mathrm{mg}$ per day) and then risperidone (day $21,1 \mathrm{mg}$ bd increasing to $4 \mathrm{mg} \mathrm{bd}$ ) being started. Threats and an assault led to droperidol being added on day 23 of admission (increasing gradually to $30 \mathrm{mg}$ tds).

On day 29 of admission he became still more aggressive and a decision was made to stop his clonazepam and risperidone. He was moved to a regional secure unit the following day after being given sodium amytal $500 \mathrm{mg}$ intramuscularly.

On arrival he was surprisingly calm and cooperative. His blood pressure was $230 / 150$ and pulse $100 / \mathrm{minute}$. He had a frontal headache, but there were no clinical abnormalities that could explain the hypertension. Twenty-four hours later his blood pressure had fallen to $165 / 115$ and at 72 hours normalised at $125 / 90$. Investigations failed to provide an explanation for the hypertensive episode, indeed the only abnormality was a urine drug screen positive for cannabis.

Neither sodium amytal nor benzodiazepines have been reported to cause hypertension, and cannabis actually lowers standing blood pressure (Goodman \& Gilman, 1985). Risperidone blocks $D_{2}$, alpha $a_{1}$ and $5-\mathrm{HT}_{2}$ receptors and could have contributed to the hypertensive episode described in this patient, 